\title{
ARE WE RATIONAL WHEN IT COMES TO RATIONALITY?
}

Review of Rationality and Decision Making: From Normative Rules to Heuristics, M. Hetmański (ed.), Leiden: Brill-Rodopi 2018.

\begin{abstract}
The paper is a review of the book Rationality and Decision Making: From Normative Rules to Heuristics edited by Marek Hetmański. The volume consists of eighteen chapters on different topics revolving around the common theme of rationality. The review discusses each paper, focusing more closely on some, in order to evaluate the arguments and claims that I find interesting, controversial, or surprising. Most chapters fall into the category of standard analytic philosophy with just a few lightly flirting with other philosophical traditions and one discussing José Ortega y Gasset.

Keywords: review, rationality, decision making, Gigerenzer, Kahneman, Tversky, group agent, bias, heuristics
\end{abstract}

Rationality and Decision Making: From Normative Rules to Heuristics, edited by Marek Hetmański, is a collection of eighteen papers written by different authors on topics related to the main theme of rationality and preceded by an introduction written by the editor. Most chapters are written by Polish scholars, but a significant chunk of the volume is contributed by foreign authors.

The chapters cover a wide array of issues, such as the semantics of normative discourse, collective rationality, theories of rationality, heuristics, and cognitive biases. There are also two historical chapters and one describing an empirical experiment. However, it is somewhat surprising that such a hot topic

* Institute of Philosophy, University of Warsaw, Krakowskie Przedmieście 3, oo-927 Warsaw,jmrudnicki@gmail.com. 
as the replicability of the experiments that had led to the formulation of certain purported cognitive biases, ${ }^{1}$ did not find its way into the volume.

The papers are written with the intention of presenting novel ideas, but it should be noted that in some cases the main theses are somewhat difficult to identify.

In this review, I describe each paper in turn, but given the limitations of space, only a few are discussed in more detail.

1. MARÍA JOSÉ FRÁPOLLI AND NEFTALÍ VILLANUEVA, MINIMAL EXPRESSIVISM AND THE MEANING OF PRACTICAL RATIONALITY

The chapter by María José Frápolli and Neftalí Villanueva (1-22)² is devoted to analyzing the semantic aspects of the rationality discourse. However, its main purpose is to familiarize the reader with the position the authors call Minimal Expressivism, which, as they contend, provides the right tools for dealing with the consistently problematic aspects of the expression "is rational".

The authors begin with some simple scenarios that help the reader understand the difference between factual, verbal, and normative disputes. Factual disputes, as the name suggests, have the property of being resolvable by appeal to facts, whereas verbal disputes rest on the meaning of words. According to Frápolli and Villanueva, normative disputes differ from both these types. There are no facts of the matter that can resolve normative disputes between individuals with different standards of rationality, even after the divergence becomes evident. At the same time, they do not seem to be arguments over the definitions of to know, is good or is rational either (1-3).

The point of departure for the position presented in the paper is a more standard version of expressivism that can be traced back to Allan Gibbard $(1986,1990)$. According to this view, when we say that X's decision is rational, we express two things (6):

a cognitive state: a factual belief that X's decision satisfies the requirements of a system of norms, $\mathrm{N}_{1}$;

a normative state: that we accept $\mathrm{N}_{1}$.

\footnotetext{
${ }^{1}$ See especially some critical literature on the so-called priming effects: Pashler et al. 2012, Doyen et al. 2012, Harris et al. 2013, Earp et al. 2014.

${ }^{2}$ All page numbers unaccompanied by the name of the author or the year of publication refer to the volume under review.
} 
The authors discuss two problems with Gibbard's position. The first difficulty is motivated by Saul Kripke's (1982) well-known discussion of the content of cognitive states allegedly expressed by the utterances under discussion. The worry is that it is doubtful that any facts of the matter can settle the question of whether or not a certain behavior accords with a given set of norms. This casts doubt on the alleged factual character of beliefs expressed by the utterances belonging to the rationality discourse (7).

The second counterargument comes originally from John MacFarlane (2014) and its crux is the following. Let's first imagine that two individuals, $A$ and $B$, have different norms of rationality, $\mathrm{N}_{\mathrm{A}}$ and $\mathrm{N}_{\mathrm{B}}$ respectively, and that they are both faced with making a judgement whether S's action is rational. Additionally, S's action happens to be rational according to $\mathrm{N}_{\mathrm{A}}$ but not according to $\mathrm{N}_{\mathrm{B}}$. From this it follows that A judges the action to be rational and $B$ judges it not to be rational. Intuitively, this is a clear case of disagreement. It is important to observe, however, that the impression of disagreement cannot stem from the difference between A's and B's cognitive states, since they are compatible with each other. In other words, there should be no conflict generated by the fact that A's rationality standards are met and B's are not. At least as long as those standards differ. This suggests that the disagreement must be produced by the divergence between A's and B's norms themselves or, in other words, by the content of their normative states (7-8).

But what happens if we introduce a third person, $\mathrm{C}$, who accepts the same norms as $B$ does $\left(\mathrm{N}_{\mathrm{B}}\right)$, but judges the facts differently and arrives at the conclusion that $\mathrm{S}$ does meet the requirements of $\mathrm{N}_{\mathrm{B}}$ ? After we granted that the disagreement between A and B stemmed from the divergence between $\mathrm{N}_{\mathrm{A}}$ and $\mathrm{N}_{\mathrm{B}}$, our theory should predict a disagreement between A and C, too. But this would contradict our intuitions according to which $\mathrm{A}$ and $\mathrm{C}$ agree about $\mathrm{S}$ 's action being rational and, therefore, puts Gibbard's view in a tough spot (8-9).

Minimal Expressivism is a position intended to preserve the intuitions behind Gibbard's expressivism while avoiding its shortcomings. The view consists of two main claims: (1) "is rational" is a higher-level notion and (2) not all expressions affect narrowly construed Kaplanian content (lekton), but some affect the circumstances of evaluation (which together with the Kaplanian content produce an Austinian proposition). The important feature of this position is that it allows the functions of propositions (is rational being an example) to affect only the latter. Granted this, we see that Minimal Expressivism does not inherit the two-tier analysis characteristic of original expressivism. This is because "is rational" cannot add anything to the factual side (the truth-conditions) of the proposition believed by the author of the utterance and, therefore, leaves the norm-following element missing (10-19). 
This is a desired result given that the Gibbard view's vulnerability to attacks based on Kripkean observations. The corrections proposed by Frápolli and Villanueva also provide a solution to the problem put forward by MacFarlane. According to the new view, however, the meaning of "is rational" can be traced by looking at the inferential links between claims from within the rationality discourse and other claims. Two people agree on the rationality of a certain action if the consequences stemming from their rationality claims are similar in important ways (19).

What I, personally, miss in this chapter is at least a modest argument for how the transfer of the norm-following element from the lekton to the circumstances of evaluation is supposed to provide a solution to the Kripkean worry. It seems that, even on the Minimal Expressivist view, for a rationality discourse proposition about a certain action to come out true, the action still needs to be in accord with the rules assumed by the author of the utterance. The sole fact that we now locate this part in a different place in our semantic machinery does not change anything in this regard.

2. MAREK HETMAŃSKI, GROUP DECISION MAKING AS RATIONAL UNDERTAKING: RATIONALITY ATTRIBUTED OR DESCRIBED?

The paper by Marek Hetmański (23-53) is an attempt to analyze how the notion of being or acting rational(ly) is predicated of groups of people or institutions, such as political bodies or corporate organizations.

The author begins by looking at the acts of figurative speech that treat groups and other complex bodies as individuals (e.g., financial markets reacted, the government decided). While doing so, Hetmański draws on to the modern classics of metaphor analysis - George Lakoff and Mark Johnson (1999).

The remaining parts of the chapter are devoted to directing the reader's attention towards other possible ways of predicating rationality of groups, which remain the focus of the paper throughout. Those different perspectives correspond with the most widely celebrated theoretical approaches towards identifying incarnations of rationality, both normative and descriptive (Kahneman, Tversky 1983, Gigerenzer 2015).

Hetmański's chapter constitutes a very general introduction to how people do, or might want to, think about the rationality of groups. It remains a bit parsimonious when it comes to the author's own evaluative claims and leaves the reader who might be skeptical about the heuristics-motivated rationality attributions without any additional arguments for their acceptance. 
3. BARBARA TRYBULEC, IT TAKES EFFORT TO BE (COLLECTIVELY) RATIONAL: GROUP AS A REASONING AGENT

The topic of group rationality is also the focus of the chapter by Barbara Trybulec. The idea behind her paper is to provide an alternative to the view of group agency and their epistemic autonomy offered by Philip Pettit (2004).

Before the author gets to the final parts in which her proposal is laid out, the reader is introduced to a brief historical outline of the debate on group agency. Trybulec, following List and Pettit (2011), discusses briefly the authorization theory, according to which group agents come into existence when each member of a collection of individuals licenses the group to speak in the individual's name (56). A view that also gets covered in the outline is the animation theory inspired by Hegel's philosophy. This position attributes to group agents a kind of emergent qualities that go beyond the qualities of its parts taken together (56-57).

Both Pettit's (2004) position critiqued by Trybulec and her own view could be categorized as lying closer to the authorization side of the spectrum. Having said that, it must be noted that there is one relevant aspect of Pettit's theory that brings it one step closer to the ideas normally associated with the animation view. It is the so-called discontinuity thesis, which says that for a collective body to form a true group agent - i.e., to be capable of possessing its own intentional states - it needs to be able to sometimes make judgements that are not shared by any of its members (63-64).

The problem with the discontinuity thesis seems to be that it comes in conflict with a plausible requirement for group rationality, namely the responsiveness to its members. If this demand is not met, a reasonable objection can be made that the group agent is not sensitive to relevant evidence (64-65). Trybulec's solution is to keep responsiveness and, therefore, abandon the discontinuity thesis. The idea she offers in replacement for the emergent-like result of the discontinuity thesis is one that treats group agency as being distributed among its elements that are combined in an adequate way (69):

group's intentional states, are constituted by a group's organizational structure that determines individuals' decisions. Group beliefs, plans and desires are shared by all group members even though some of them could not even know their contents (some members must however control them).

The tension between the discontinuity thesis and the responsiveness requirement is definitely an unwelcome result for a proponent of group agency. The problem with Trybulec's purported solution seems to be that, after discarding discontinuity, the reasons for accepting group agents that we are left with come dangerously close to pragmatic considerations for allowing sim- 
pler descriptions of agency. It is doubtful whether this result, recognized by the author herself (68-69), can be convincing for people with reductionist inclinations.

4. SOFIA MIGUENS AND JOÃO ALBERTO PINTO, SEEING WHAT A "SCIENCE OF RATIONALITY” FOUNDERS ON (WITH A LITTLE HELP FROM DONALD DAVIDSON)

The chapter by Sofia Miguens and João Alberto Pinto discusses the question, originally put forward by Davidson (2004), of whether there could be a science of rationality.

The authors begin by describing the vast Davidsonian project of putting together the philosophical problems of thought, meaning, and action (78-80). For Davidson, the central notion that serves as a base for uniting the aforementioned triad is rationality. Given the peculiar role the notion of rationality plays in Davidson's conception of being assumed in order to allow us to disentangle the other three, it should be clear why Davidson's own answer to the question of the possibility of a science of rationality is negative (82).

In order to reject this negative conclusion, Miguens and Pinto appeal to the pragmatist theory of rationality offered by Stephen P. Stich (1990). This framework, according to the authors, succeeds in introducing philosophical grounding for scientific research programs such as that pursued by Gerd Gigerenzer (89-90).

5. ÁNGELES J. PERONA, SOFT RATIONALITY AND RETICULATED UNIVERSALITY: REFLECTING ON THE DEBATE BETWEEN R. RORTY AND H. PUTNAM

In her paper, Ángeles J. Perona explores the idea of enriching reflection on rationality with the notion of emotions, understood as experience coming from interactions with the surrounding culture and natural environment. The author's starting point is the debate between Putnam and Rorty, analyzed by Perona at length. The aim of the comparison is to show that even among the neopragmatic family there was a conflict of how much normativity should be allowed into the notion of rationality (96-107).

Perona's position, inspired by Wittgenstein's late philosophy, employs the idea of family resemblance in order to arrive at a third-way position she calls naturalist-social. The framework stemming from Philosophical Investigations is used to avoid the problems identified earlier in Rorty's and Putnam's 
ways of justifying norms, namely sociological factualism and apriorism respectively (112-116).

Manuel de Pinedo tries to convince the reader that, in contrast to the traditional view, an unreflective action can be rational. He generally follows a normative approach to rationality reminiscent of Davidson's.

The example of an unreflective rational action the author uses throughout the paper is Roger Federer's skillful volleying. According to Pinedo, even though the tennis player does not possess explicit reasons for performing his shots exactly the way he does, we should still regard his actions to be rational. This is because Federer is willing to reflect upon his game afterwards as well as listen to his coach who is responsible for analyzing it. Federer's capacity to recognize the coach as a good source of advice is, according to Pinedo, a good reason for ascribing rationality to his future actions on the tennis court. Such an interaction between an agent and an advice-giver aimed at improving the agent's performance can be treated as distributed embodied rationality, a notion that already appeared in Trybulec's chapter (125).

\section{RUI SAMPAIO DA SILVA, PSYCHOLOGY AND THE NORMS OF RATIONALITY}

The chapter by Rui Sampaio da Silva proposes a novel prescriptive theory of human rationality that includes, what the author calls, an education criterion.

The beginning of the paper concerns the well-known examples of people's cognitive shortcomings described by Daniel Kahneman and Amos Tversky (1982, 1983) and Peter Wason (1966) (141-144). The purpose of reminding these famous experimental results is to convince the reader that the traditional normative view of rationality expecting humans to conform to the demands of, among others, logic and probability theory is too stringent and forces us either to conclude that the members of our species are not rational after all or to come up with suspicious-looking evasions in order to restore human rationality (147-149).

After expressing his reasons against siding with the descriptive notion of rationality (151-155), da Silva proceeds to describe his positive proposal. The prescriptive and normative approaches are closely related. The main difference is that the former accepts our cognitive and psychological constraints. It retains 
some intuitions behind the normative approach, though, by disagreeing to accept those constraints definitively. The crux of the prescriptive perspective, as offered by da Silva, is to come up with such norms of rationality that would demand more from individuals but could also be introduced into the general system of education and therefore be attainable for most people. This way we are promised to get the best of both worlds - norms of rationality that respect human cognitive constraints but still do not allow obvious violations of, say, basic logic (155-159).

An obvious problem with this proposal is that it presupposes that some norms must exist prior to prescriptive ones. Although da Silva offers a response to this objection (156), I cannot see how his remark can be of any help without significant elaboration.

It seems to me that there is at least one additional outright problem with the view. Namely, it does not allow us to distinguish between the rationality of a person that merely conforms to the demands of the prescriptive norm (such as deductive logic and the conjunction principle) and a person that is capable of performing much more demanding operations that are not required by the prescriptive norm (like being able to use the Bayes theorem in practice)? On this view both agents are rational and we lack normative tools to point to the difference between them, which is a highly counterintuitive result.

8. JESÚS ZAMORA-BONILLA, INFERENTIALISM, RATIONALITY, AND VALUE-DRIVEN EPISTEMOLOGY

Jesús Zamora-Bonilla proposes a theory of knowledge stemming from "an inferentialist view of the embeddedness of psychological states in a web of normative statuses" (163).

Before the author gets to the positive part of the paper, he criticizes the view supported by, among others, value-driven epistemology, according to which the value of the state of knowing is higher than that of the state of believing something true. 3

One of the arguments offered by Zamora-Bonilla against that view can be formulated as the following reductio (166-167):

\footnotetext{
${ }^{3}$ Even though it is not explicitly stated in the paper, it is clear that by "believing something true," Zamora-Bonilla actually means believing something true plus believing that the true belief is acquired by a reliable method (even though the method is, in fact, not reliable), or something of that sort.
} 
(1) knowing that $\mathrm{P}$ is more valuable than truly believing that $\mathrm{P}$ [assumption];

(2) given that $\mathrm{P}$ is a true proposition listing the winning numbers in a lottery with a prize of $€ 100$, knowing $P$ is more valuable than believing in a true proposition (Q) listing the winning numbers in some lottery with a prize higher than $€ 100$ [from (1)];

knowing and believing truly are internally indistinguishable, therefore the difference in states cannot affect the preference of a prize higher than $€ 100$ to that of exactly $€ 100$;

Conclusion: Since, intuitively, everyone prefers the higher prize, it follows that knowing that $\mathrm{P}$ is not more valuable than truly believing that $\mathrm{Q}$, and therefore that also (1) is false [since (2) follows from (1) and is unintuitive we arrive at a contradiction].

9. AGNIESZKA LEKKA-KOWALIK, RATIONAL DECISIONS AND WISE DECISIONS: TWO NAMES FOR THE SAME THING?

Agnieszka Lekka-Kowalik tries to answer the question of whether rational decisions and wise decisions form the same set. In fact, the author is interested only in the hypothesis that every rational decision is a wise decision, while the implication going the other way is left for another time (192). The answer reached by Lekka-Kowalik is negative - there are rational decisions that are not wise.

Her line of argumentation rests on a scenario resembling the prisoner's dilemma, but with a significant twist. Here, one of the suspects, call her B, is overcome by contrition and actually wants to go to prison, while the other (A) wants to remain free. The resulting situation is as follows. If they both confess, they go to prison for five years. If none of them confesses, they both remain free. If one confesses and the other does not, the former is free to go, while the latter goes to prison for ten years. The decisions they finally make are: A does not confess because she wants to remain free and counts on B's desire to also escape justice; $\mathrm{B}$, on the other hand, chooses to confess since her goal is for justice to prevail. The resulting situation is that they both get what they wanted to avoid - A is sentenced to ten years in prison and B is allowed to remain free (185).

Lekka-Kowalik analyzes different possible takes on the rationality of their decisions and, after rejecting the idea of they are either being both irrational 
or one is being rational and the other irrational, concludes that they both need to be considered rational (187).

The final step in her line of thought is that wisdom often has a social aspect. This social aspect, understood as, for example, willingness for the truth and justice to prevail and for the society to retain faith in the legal system, is part of B's motivation for choosing to confess. It is also definitely absent from A's reasons to act the way she does. From this, it follows that B's decision is wise, while A's is not. Since it was already said that they are both rational, it follows that rationality does not imply wisdom (188-192).

My problem with this argumentation, even though I do not disagree with the conclusion, is that given the goals of A and B, the most natural way of assessing their decisions is to say, contrary to what Lekka-Kowalik claims, that they are irrational. The reason, however, is different than the one she analyzes and refutes: the goals not being achieved. The much better reason is provided by simple decision theory. If A confesses, she either goes to prison for five years (if B also confesses) or is free (if B does not confess). If A does not confess, she either goes to prison for ten years (if B confesses) or is free (if $B$ does not confess). If $B$ confesses, she either goes to prison for five years (if A also confesses) or she is free (if A does not confess). If B does not confess, she either goes to prison for ten years (if A confesses) or she is free (if A does not confess).

Clearly, if A's goal is to minimize her imprisonment and B's is to maximize it in order for justice to prevail, the choices that let them best achieve this are, for A to confess and for B to refrain from confessing. This result is the opposite of what Lekka-Kowalik predicts as the rational outcome.

It is also worth noting that, contrary to the standard prisoner's dilemma, in this modified scenario, if both of our suspects behave rationally (according to my analysis), they also arrive at a result that suits their individual expectations in the most efficient way $-\mathrm{A}$ is freed and $\mathrm{B}$ goes to prison for ten years.

10. MONIKA WALCZAK, THE MEANS-END RATIONALITY AND CONSTITUTIVE ELEMENTS OF ACTION

Monika Walczak presents an analysis of the notion of practical knowledge. The author approaches the problem from the perspective of Nicholas Rescher's (1966) view of action.

The main thought behind the paper is that practical rationality should not be understood simply as means-end rationality. Rather, it should be extended 
by the addition of such elements as the agent, act-type, setting of action, and rationale of action (201).

11. JAN FRANCISZEK JACKO, MORAL CONDITIONS FOR METHODOLOGICALLY RATIONAL DECISIONS

The purpose of chapter 11, written by Jan Franciszek Jacko, is to make a case for the view that respecting autotelic moral values is a requirement for making decisions that are methodologically rational. The author discusses the arguments for the idea he defends that come from the work of a heterogeneous group of philosophers, including Aristotle, Immanuel Kant, Max Scheler, Max Weber, Tadeusz Kotarbiński, Jean-Paul Sartre, and Jürgen Habermas. In particular, Jacko underlines that this view is assumed by some philosophers in their phenomenological analyses of the process of decision making.

12. ANTÓNIO ZILHÃO, COGNITION AND RATIONALITY: WRITING STRAIGHT WITH CROOKED LINES?

António Zilhão begins his paper by describing the four main approaches towards rationality present in the current debates: unbounded rationality, optimization under constraints, heuristics and biases, and ecological rationality (225-227).

The author reconstructs the main areas of conflict between them (228229) and then presents what he calls the third-way view in rationality theory. This position is called Brute Rationality and was originally proposed by Keith Stanovich (2013). The theory is finally criticized by Zilhão and ecological rationality is mildly endorsed.

13. MARCIN RZĄDECZKA, WHEN BEING RIGHT IS NOT GOOD ENOUGH: HOW SYSTEMATIC COGNITIVE BIASES AFFECT DECISION MAKING STRATEGIES

Marcin Rządeczka introduces a division of cognitive biases into two categories: cognitive artifacts and cognitive adaptations. His paper is focused on discussing the second category that includes the biases stemming from the evolutionary mechanisms of oversensitization to certain disease-associated or danger-associated stimuli (240). 
In his discussion, he points the reader's attention to the evolutionary reasons for the lesser risk of false positives than of their correspondent false negatives that seem to explain biases such as food aversion or xenophobia (244-247). The author is also optimistic regarding the possibility of human cognitive improvement by becoming less susceptible to the aforementioned biases (249).

Although the paper is mostly descriptive, the author makes the following evaluative claim that I find problematic (249):

The very existence of so many and such diverse systematic biases demonstrates that, from an evolutionary point of view, an optimal decision making strategy is not always about applying flawless logic or making precise estimations. When the risk of error is asymmetrical, it is simply better to be biased towards the less costly type of error.

This passage shows an implicit assumption of the author that it is impossible to incorporate the cost of error into the standard rationality calculus the normally rests on flawless logic and precise estimations. Without any additional arguments for this assumptions, Rządeczka is simply begging the question against the more normative approaches towards rationality.

14. ANNA WÓJTOWICZ AND JAN WINKOWSKI, HEURISTICS: DANIEL KAHNEMAN VS GERD GIGERENZER

In their paper, Wójtowicz and Winkowski aim to come up with a universal understanding of the notion of heuristic that would be acceptable for people coming from three different theoretical backgrounds: the heuristics and biases program, the fast and frugal heuristics program, and computer science.

The chapter begins with a simple introduction into those three different perspectives and their intuitions behind the notion in question (254-263). The positive part of the paper manages to deliver what it promises - a purported universal definition of a heuristic (269).

The authors also propose a simple, but intuitively appealing, measure for heuristics' reasonability. It takes into consideration (1) how close the result provided by a heuristic is to the result provided by the normative method producing the theoretically optimal result, as well as (2) how much simpler it is $(270-271)$.

The paper ends with some remarks on the consequences that the proposed understanding of the notion of heuristic has for the notion of rationality and makes use of the distinction for coherence rationality and correspondence rationality, proposed by Kenneth Hammond (1990) (272-275). 
15. JOANNA SOKOŁOWSKA, RATIONALITY AND PSYCHOLOGICAL ACCURACY OF RISKY CHOICE MODELS BASED ON OPTION- VS. DIMENSION-WISE EVALUATION

Chapter 15, written by Joanna Sokołowska, is the only purely empirical paper included in the volume. The author discusses the results of two experiments.

One of the findings is that dimension-wise transitions dominate option-wise transitions. Sokołowska concludes that her results disagree with the understanding of rationality characteristic of decision sciences and psychology.

\section{MARCIN TRYBULEC, RATIONALITY IN THE MATERIAL WORLD}

Marcin Trybulec's paper focuses on two models of the relationship between artifacts and cognition: amplification and transformation. According to the former, artifacts are means of enhancing the potential of individuals. The latter, on the other hand, claims that artifacts manage to change the general situation in which an individual operates (304).

The author supports the transformation model and, in the final parts of the paper, discusses the results of an experiment, that according to him constitute an illustration for why the model he prefers is superior (308-311).

17. ARTUR KOTERSKI, NEURATH'S DECISIONISM AND THE EARLIEST REVIEWS OF LOGICAL EMPIRICISM

Artur Koterski's chapter is concerned with giving a historical overview of Otto Neurath's decisionism and situating it in relation to the views of the Vienna Circle as a whole, as well as, the criticism of logical positivism by Roman Ingarden, Karl Popper, and Julius Rudolph Weinberg.

The author defines decisionism in the following way (p. 318):

Decisionism in Neurath's sense is a view that making free decisions in science, both practical and theoretical, is rational when no justification is available.

Koterski's claim is that the fact that Neurath had held the view long before logical positivism was fully formed, shows that the standard interpretation, according to which conventionalism was not present within the logical positivist movement in the early days, is wrong. 

RATIOVITALISM BY JOSÉ ORTEGA Y GASSET

The last chapter of the volume, written by Krzysztof Polit, discusses the views of Ortega y Gasset. Discussing his position, ratiovitalism, allows Polit to take a critical look at the modern idea of Western rationality. The very heart of the criticism comes down to the observation that our accurate concepts have a hard time describing our ever-changing reality. The author admits being inspired by interpretations of Ortega by such scholars, as Antonio Pérez Quintana (2005) and Anastasio Ovejero Bernal (2000).

\section{SUMMARY}

Overall, the book discusses a very wide range of topics associated with the theme of rationality, which alone shows how vast that subject has become. The reader is given an opportunity to dive into some aspects of the current debates, as well as, perhaps, a rough understanding of the importance of the topic in the history of Western thought.

As could be expected with eighteen papers that the volume consists of, the quality of the chapters is almost as diversified as their topics. That said, it needs to be noted that there are papers in this book that fit nicely within the current trends of thinking in certain areas of philosophy, and also that several authors managed to propose points and arguments that are worth analyzing.

\section{BIBLIOGRAPHY}

Davidson D. (2004), Problems of Rationality, Oxford: Oxford University Press.

Doyen S., Klein O., Pichon C.-L, Cleeremans A. (2012), "Behavioral Priming: It's All in the Mind, but Whose Mind?” PLoS ONE 7(1): e29081.

Earp B. D., Everett J. A. C., Madva E. N., Hamlin J. K. (2014), “Out, Damned Spot: Can the Macbeth Effect be Replicated?” Basic and Applied Social Psychology 36, 91-98.

Gibbard A. (1986), "An Expressivistic Theory of Normative Discourse," Ethics 96(3), 472-485.

Gibbard A. (1990), Wise Choices, Apt Feelings, Oxford: Oxford University Press.

Gigerenzer G. (2015), Simply Rational: Decision Making in the Real World, Oxford: Oxford University Press.

Hammond K. R. (1990), Functionalism and Illusionism: Can Integration Be Usefully Achieved? [in:] Insights in Decision Making: A Tribute to Hillel J. Einhorn, R. M. Hogarth (ed.), Chicago: University of Chicago Press. 
Harris C. R., Coburn N., Rohrer D., Pashler H. (2013), "Two Failures to Replicate HighPerformance-Goal Priming Effects," PLoS ONE 8(8): e72467.

Kahneman D., Tversky A. (1983), "Extensional versus Intuitive Reasoning: The Conjunction Fallacy in Probability Judgment," Psychological Review 90(4), 293-315.

Kripke S. (1982), Wittgenstein on Rules and Private Language, Cambridge, MA: Harvard University Press.

Lakoff G., Johnson M. (1999), Philosophy in the Flesh: The Embodied Mind and Its Challenge to Western Thought, New York: Basic Books.

List Ch., Pettit P. (2011), Group Agency: The Possibility, Design and Status of Corporate Agents, Oxford: Oxford University Press.

MacFarlane J. (2014), Assessment-Sensitivity: Relative Truth and Its Applications, Oxford: Oxford University Press.

Ovejero Bernal A. (2000), Ortega y la posmodernidad, Madrid: Biblioteca Nueva.

Pashler H., Coburn N., Harris C. R. (2012), "Priming of Social Distance? Failure to Replicate Effects on Social and Food Judgments," PLOS ONE 7(8): e42510.

Pérez Quintana A. (2005), El raciovitalismo. La cultura como función de la vida, Oviedo: Eikasia Ediciones.

Pettit P. (2004), Groups with Minds of Their Own [in:] Socializing Metaphysics, F. F. Schmitt (ed.), New York: Rowman and Littlefield Publishers, 167-193.

Rescher N. (1966), Appendix II. Aspects of Action [in:] The Logic of Decision and Action, N. Rescher (ed.), Pittsburgh: University of Pittsburgh Press, 215-219.

Stanovich K. E. (2013), "Why Humans Are (Sometimes) Less Rational than Other Animals: Cognitive Complexity and the Axioms of Rational Choice," Thinking \& Reasoning 19(1), 1-26.

Stich S. (1990), The Fragmentation of Reason: Preface to a Pragmatic Theory of Rationality, Cambridge MA: MIT Press.

Tversky A., Kahneman D. (1982), Judgment under Uncertainty: Heuristics and Biases [in:] Judgment under Uncertainty: Heuristics and Biases, D. Kahneman, P. Slovic, A. Tversky (eds.), Cambridge: Cambridge University Press, 3-20.

Wason P. (1966), Reasoning [in:] New Horizons in Psychology, B. Foss (ed.), Harmondsworth: Penguin Books, 135-151. 